\title{
Tuz ve kuraklık stresi altında yetişen farklı patlıcan anaç/kalem kombinasyonlarının bazı özellikleri arasındaki ilişkiler
}

\section{Relationships between some characteristics of different eggplant rootstock/scion combinations that growned under salt and drought stresses}

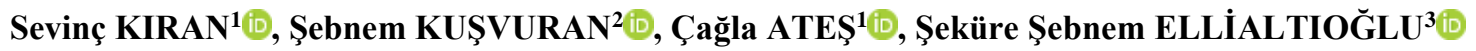 \\ ${ }^{1}$ Toprak Gübre ve Su Kaynakları Merkez Araştırma Enstitüsü, Ankara \\ ${ }^{2}$ Çankırı Karatekin Üniversitesi, Kızılırmak Meslek Yüksekokulu, Çankırı \\ ${ }^{3}$ Ankara Üniversitesi, Ziraat Fakültesi, Bahçe Bitkileri Bölümü, Ankara \\ Sorumlu yazar (Corresponding author): S. Kıran, e-posta (e-mail): sevinckiran@tgae.gov \\ Yazar(lar)e-posta (Author e-mail): skusvuran@gmail.com, caglaates@hotmail.com, ellialti@agri.ankara.edu.tr
}

\section{MAKALE BILLGİSİ}

Alınış tarihi 13 Haziran 2019

Düzeltilme tarihi 30 Eylül 2019

Kabul tarihi 02 Ekim 2019

Anahtar Kelimeler:

Kuraklık

Tuzluluk

Korelasyon

Anaç

Genotip

\section{$\ddot{\mathbf{o z}}$}

Bu çalışmada, tuza toleransı yüksek 2 ticari patlıcan anacı üzerine aşılı ve aşısız olarak kendi kökleri üzerinde yetiştirilen 4 patlıcan genotipine ait bitkiler kuraklık ve tuz stresi koşulları altında yetiştirilmiş ve bazı özellikleri incelenmiştir. Bu özellikler arasındaki ilişkiler değerlendirilmiştir. Araştırma, sıcaklık ve nem kontrolünün sağlandığı cam serada yürütülmüştür. Kuraklık stresi, saksılarda yarayışlı su seviyesinin \%50 düzeyinde tutulması ile sağlanmıştır. Tuz stresi ise, elektriksel iletkenlik (EC) değeri $6 \mathrm{dS} \mathrm{m}^{-1}$ olan ve $\mathrm{NaCl}$ ile hazırlanmış su kullanılarak oluşturulmuştur. Kuraklık ve tuz stresi ortamında yetiştirilen bitkilerden elde edilen morfolojik, fizyolojik, verim ve kalite özellikleri arasındaki ilişkiler korelasyon analizi ile ayrı ayrı değerlendirilmiştir. Gövde yaş ve kuru ağırlıkları, kök yaş ağırlığı ve gövde kalınlığı gibi fiziksel özellikler; kuraklık ve tuz stresi altında pozitif yönde ve yüksek seviyede korelasyon sergilemiştir. Kuraklık ve tuz stresine bağlı olarak meyve kuru ağırlığı, meyve suyu EC değeri ve titrasyon asitliği ile birlikte yüksek korelasyon katsayıları vermiştir. Çalışma sonucunda, yüksek korelasyon katsayısına sahip olan parametrelerin tuz ve kuraklık streslerinin ortaya koyduğu etkilerin belirlenmesinde önemli ve etkin kriterler olduğu belirlenmiştir.

\section{ARTICLE INFO}

Received 13 June 2019

Received in revised form 30 September 2019

Accepted 02 October 2019

\section{Keywords:}

Drought

Salinity

Correlation

Rootstock

genotype

\begin{abstract}
In this study was investigated the relationships between some parameters of 4 eggplant genotypes grafted onto salt tolerance 2 commercial eggplant rootstocks and non-grafted plants under drought and salt stress conditions. The study was carried out in a glass greenhouse where the temperature and humidity were regulated automatically. For drought stress, plantavailable water, $50 \%$ was consumed for irrigation. The salt stress was generated by using water prepared with $\mathrm{NaCl}$ having electrical conductivity (EC) of $6 \mathrm{dS} \mathrm{m}^{-1}$. The correlation between morphological, physiological, yield and quality parameters obtained from plants grown in drought and salt stress conditions were evaluated separately by correlation analysis. Physical parameters, such as shoot fresh and dry weights, root fresh weight and stem diameter, showed positive and high correlation under drought and salt stress. Due to drought and salt stress, fruit dry weight, fruit juice EC and titration acidity gave high correlation coefficients. As a result of the study, it was determined that the parameters having high correlation coefficient are important and effective criteria for determining the effects of salt and drought stresses.
\end{abstract}

\section{Giriş}

Tuz ve kuraklık stresleri, kurak ve yarı kurak bölgelerde ürün kalitesi ve verimini düşüren önemli çevresel faktörlerdir. Ülkemizde geniş bir varyasyona sahip olan patlıcan (Solanum melongena L.) bitkisi, yaz aylarında genellikle açık alanda, kış aylarında ve sonbaharda ise örtüaltında yetiştirilmekte olup, birçok sebze türüne göre kurağa daha tolerant olmakla birlikte, tuzluluğa orta tolerant $\left(1.1 \mathrm{dS} \mathrm{m}^{-1}\right)$ bir sebze olarak sinıflandırılmaktadır (Rady ve El-Azeem 2018). Küresel 
ısınmanın sonucu olarak yağışların azalması ve su kaynaklarının sınırlanması kuraklığı da beraberinde getirmektedir. Kurak ve yarı kurak alanlarda evaporasyonun yüksek oluşu nedeni ile sular, toprak yüzeyinden kaybolurken beraberinde taşıdıkları tuzları toprak yüzeyinde veya yüzeye yakın kısımlara birakmaktadır (Richards 1954). Kuraklik ve tuz streslerinin transpirasyon, stomatal iletkenlik ve fotosentez oranları gibi morfolojik ve fizyolojik faaliyetlerin üzerinde önemli ölçüde gerileme yarattığ 1 , buna bağlı olarak biyokütle veriminde azalmaya sebep olduğu rapor edilmiştir (Penellaa ve ark. 2017). Bununla birlikte kuraklık ve tuz stresi koşulları meyve veriminde stresin süresi ve şiddetine bağlı olarak değişen oranlarda azalmaya neden olurken; kuru madde, çözünür şeker içeriği ve $\mathrm{C}$ vitamini gibi kalite parametrelerinin etkilendiği birçok çalışmada ifade edilmiştir (Ünlükara ve ark. 2015; Kyriacou ve ark. 2017). Bu stres faktörlerine karşı dayanıklı çeşitlerin 1slahı uzun vadede daha kalıcı bir önlem olarak görülmekle birlikte, bu yöntem maliyetli ve zaman alıcıdır. Bu nedenle alternatif bir yöntem olarak aşılı fide kullanımı giderek artış göstermiştir. Aşılama ile stres altındaki bitkilerin yüksek yaprak su potansiyeli, stoma iletkenliği, fotosentez oranı ve verime sahip olduğu (Kıran ve ark. 2017a), toplam verim, pazarlanabilir verim, ortalama meyve ağırlığında artışa neden olduğu (Talhouni ve ark. 2017; Koleška ve ark. 2018), kuru madde ve çözünür şeker içeriğini artırdığı ifade edilmiştir (Radicetti ve ark. 2016; Kyriacou ve ark. 2017). Bu çalışmanın amacı, kuraklık ve tuz stresi koşulları altında aşılı ve aşısız patlıcan genotiplerinin bazı morfolojik, fizyolojik özellikleri ile verim ve meyve kalite özellikleri arasındaki ilişkilerin ortaya konulmasidır.

\section{Materyal ve Yöntem}

$\mathrm{Bu}$ çalışma Toprak Gübre ve Su Kaynakları Merkez Araştırma Enstitüsü'nde kontrollü cam sera koşullarında gerçekleştirilmiştir. Yetiştirme ortamında, sera içi sıcaklığının $26-18^{\circ} \mathrm{C}$ (gündüz/gece) ve nispi nemin \%50-55 olmas 1 sağlanmıştır. Çalışmada bitkisel materyal olarak önceki çalışmalarda tolerant olduğu belirlenen Mardin Kızıltepe (MK) ve Burdur Merkez (BM) ile hassas olduğu belirlenen Artvin Hopa (AH) ve Kemer (K) genotipleri kalem olarak kullanılmıştır (Yaşar 2003). Köksal ve Vista çalışmada anaç çeşit olarak kullanılmıştır. Dört farklı kalem genotipi, 2 adet ticari anaç üzerine aşlanarak toplam 8 adet anaç/kalem kombinasyonu oluşturulmuştur. Kalem olarak kullanılan genotipler ayrıca aşısız (kontrol) olarak, kendi kökleri üzerinde de yetiştirilmiştir. Patlıcan tohumları torf:perlit $(2: 1)$ karışımı içeren viyollere ekilmiş, tohum ekiminden 30 gün sonra fidelerde aşılama (tüp aşılama- tube grafting) yapılmıştır (Yetişir ve ark. 2004). Aşılamadan 30 gün sonra aş1lı ve aşısız 2-3 gerçek yapraklı fídeler $39 \times 35 \mathrm{~cm}$ boyutlarında $35 \mathrm{~L}$ hacminde içinde orta bünyeli toprak bulunan (kum: \%48.9, silt: \%17.5, kil: \%33.6, hacim ağırlı̆̆ $1.26 \mathrm{~g} \mathrm{~cm}^{-3}$; tarla kapasitesi: \%19.78, solma noktas1: \%10.62, EC: $\left.1.28 \mathrm{dS} \mathrm{m}^{-1}, \mathrm{pH}: 7.75\right)$ saksılara her saksıda bir bitki olacak şekilde dikilmişlerdir. Dikimle birlikte toprak analiz sonuçlarına göre $70 \mathrm{mg} \mathrm{kg}^{-1} \mathrm{P}_{2} \mathrm{O}_{5}$ ve $75 \mathrm{mg} \mathrm{kg}^{-1} \mathrm{~N}$, çiçeklenme döneminde ise $75 \mathrm{mg} \mathrm{kg}^{-1} \mathrm{~N}$ uygulanmıştır (Güçdemir 2006).

\subsection{Kuraklı ve tuz uygulamaları}

Kuraklık ve tuz stresinin oluşturulması için aşılamadan 45 gün sonra uygulamalara başlanmıştır. Bu aşamaya kadar tüm saksılar çeşme suyu (EC: 0.20-0.70 dS m $\mathrm{d}^{-1}, \mathrm{pH}$ : 6.8-7.10) ile tarla kapasitesi düzeyinde sulanmıştır. Kuraklık stresi $\left(\mathrm{K}_{1}\right)$ konusuna ait bitkiler, kontrol konusuna verilen suyun \%50'si düzeyinde sulanırken, kontrol $\left(\mathrm{K}_{0}\right)$ bitkileri tarla kapasitesi düzeyinde sulanmışlardır. Topraktaki nem miktarı ağırlık esasına (gravimetrik olarak) göre belirlenmiştir. Tuz stresi için bitkilere yetiştirme periyodu boyunca elektriksel iletkenliği (EC) $6 \mathrm{dS} \mathrm{m}^{-1}$ seviyesinde tuzlu sulama suyu ( $\left.\mathrm{T}_{1}\right)$ uygulanmıştır. Tuz uygulaması için $\mathrm{NaCl}$ stok solüsyonundan yararlanılmıştır. Kontrol bitkileri $\left(\mathrm{T}_{0}\right)$ temiz su ile tarla kapasitesi düzeyinde sulanırken, tuz konusunda bitkiler serbest drenaj koşullarında (tarla kapasitesi $+\% 20$ yıkama suyu) $\mathrm{NaCl}$ içeren sulama suyu ile sulanmışlardır. Çalışmada kuraklık ve tuz stresleri sonunda bitkilerin genel görünümleri Şekil 1 ve 2 'de verilmiştir.

\section{2. Ölçüm ve analizler}

Stres uygulamaları başlangıcından 20 gün sonra bitkilerde 15 gün ara ile stoma iletkenliği ve yaprak su potansiyeli (YSP) ölçülmüştür. Stoma iletkenliği SC-1 model Decagon Devices marka yaprak porometresi ile, YSP ise basınç odası cihazı ile (Model 1000, PMS Instrument Com., Albany, USA) ölçülmüştür. Hasat edilen bitkilerde gövde ve kök boyları bir şerit metre yardımıyla (cm), gövde çapı ise dijital kumpas yardımı ile $(\mathrm{cm})$ ölçülmüştür. Yaprak alanı, Licor LI- 3000A model yaprak alanı ölçer ile " $\mathrm{cm}^{2}$ yaprak" ${ }^{-1}$ " olarak belirlenmiştir.

Toplam verim, her uygulamada ilk hasattan son hasat tarihine kadar olan süre içerisinde toplanan meyveler tartılarak $\mathrm{kg} \mathrm{bitki}^{-1}$ olarak belirlenmiştir. Bunun yanı sıra ortalama meyve ağırlığ1 (g), ortalama meyve çap1 (mm) (meyvenin uç, orta ve son kısmının çapı ölçülerek ortalaması alınmıştır) meyve yaş ve kuru ağılıkları (g), meyve suyu EC ve $\mathrm{pH}$ değerleri, suda çözünebilir madde miktarı (SÇKM) belirlenmiştir. Titre edilebilir asitlik miktarı ve vitamin $\mathrm{C}$ içeriği $\left(\mathrm{mg} 100 \mathrm{ml}^{-1}\right)$ Cemeroğlu (1992)'na göre belirlenmiştir.

\section{Bulgular ve Tartışma}

\subsection{Kuraklık stresi altındaki patlican bitkilerinde incelenen parametreler arasinda elde edilen korelasyon bulgulart}

Çalışmada, gövde yaş ağırlığı ile; gövde çapı $\left(0.85^{* *}\right)$, kök yaş ağırlı̆̆ $\left(0.81^{* *}\right)$, yaprak alanı $\left(0.80^{* *}\right)$, gövde kuru ağırlığı $\left(0.79^{* *}\right)$ ve kök kuru ağırlığı $(0.74 * *)$ arasında istatistiksel bakımdan aynı yönde ve önemli düzeyde korelasyonlar bulunduğu görülmüştür (Çizelge 1). Aynı şekilde gövde kuru ağırlığı ile; gövde kalınlığı $\left(0.85^{* *}\right)$, yaprak alanı $(0.84 * *)$, kök yaş ağırlığ $1\left(0.80^{* *}\right)$ arasında da benzer ilişkiler ortaya çıkmıştır (Çizelge 1). Araştırıcılar, yaprakların kuraklık koşullardan en fazla etkilenen organlar olduğunu ve turgor kaybının ilk belirtilerden sayıldığını bildirirken, su noksanlığı karşısında hücre bölünmesi ve büyümesinde meydana gelen azalma, karbon ve azot metabolizmalarında oluşan değişimler, bitkilerde yaş ve kuru ağırlık değerlerinin de azalmasına neden olduğunu (Rezene ve ark. 2013), kuraklığın gövde ve kök yaş ve kuru ağırlı gibi bazı büyüme parametrelerini olumsuz yönde etkilediğini (Zhou ve ark. 2017) ve aşılı bitkilerde kayıpların daha az olduğunu bildirmişlerdir (Gaion ve ark. 2018). Çalışmamızda kuraklık koşulları, bitkilerin stoma iletkenliği, toplam verim ve verim parametreleri olan ortalama meyve ağırlığı ve meyve kuru ağırlığı değerlerinde de önemli düşüşlere yol açmıştır. Kuraklık stresi altında stomaların kapanması bitkilerin suyu dokularında tutmalarını sağlayan kuraklıktan kaçınma mekanizmalarından biri olmakla beraber, $\mathrm{CO}_{2}$ 'in mezofil hücrelerine girmelerini önlediğinden fotosentetik hız 

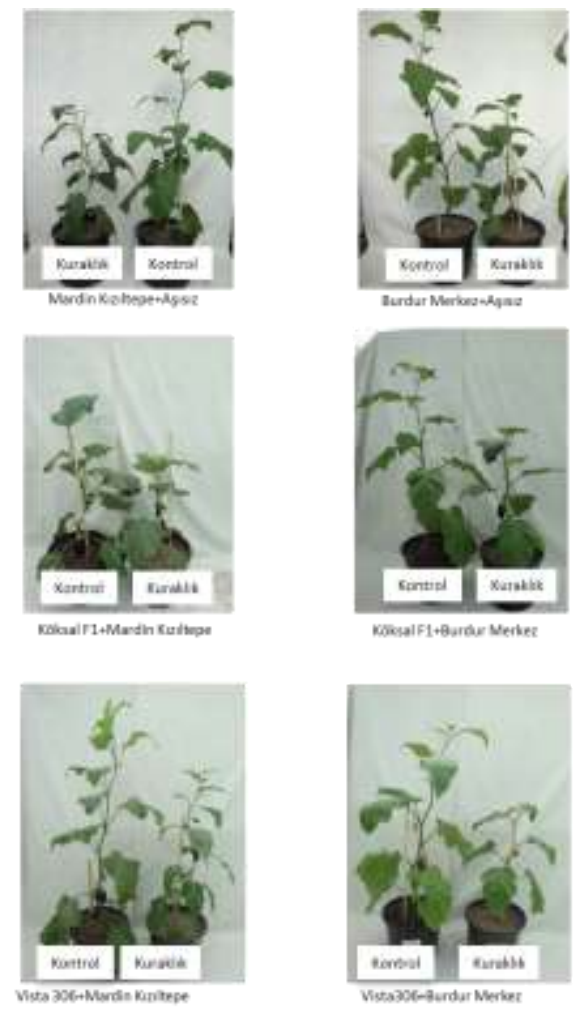
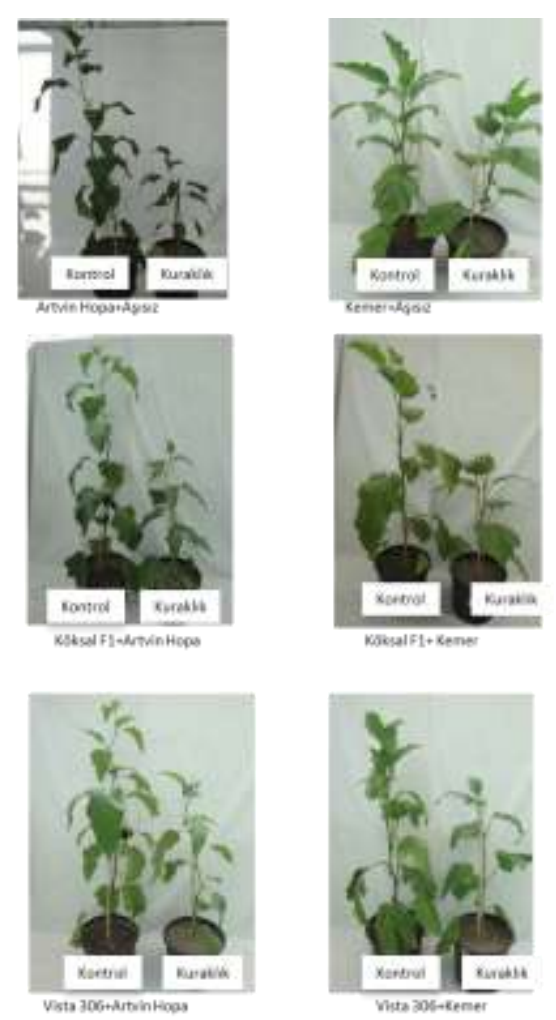

Şekil 1. Aşı1ı ve aşısız patlıcan üzerine kuraklık stresinin etkileri.

Figure 1. Effects of drought stress on grafted and non-grafted eggplant.
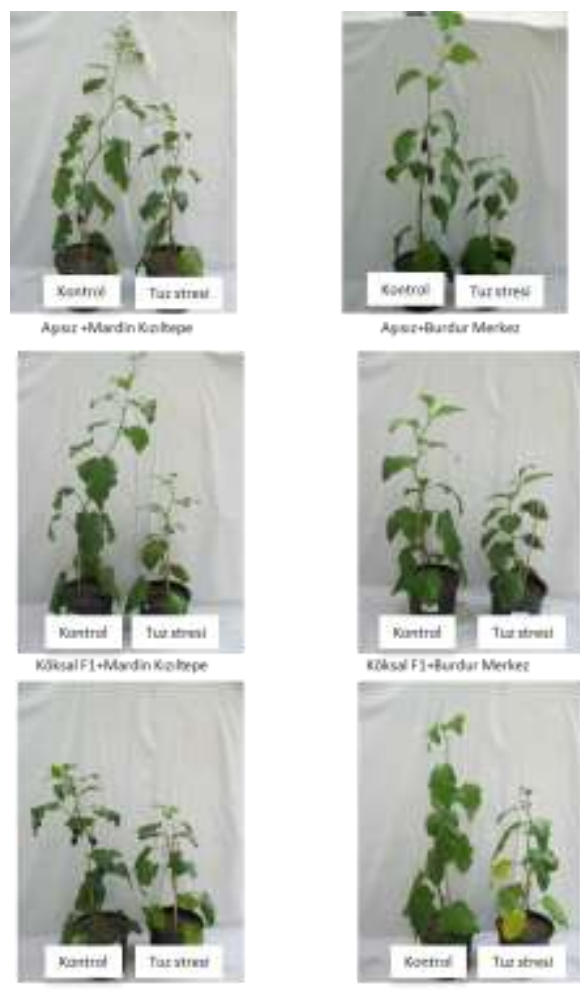

Mete 306 Mardn Kolkese
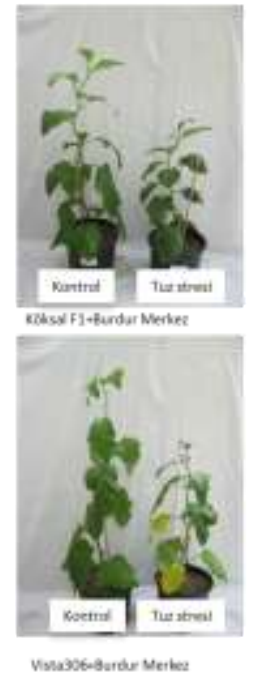
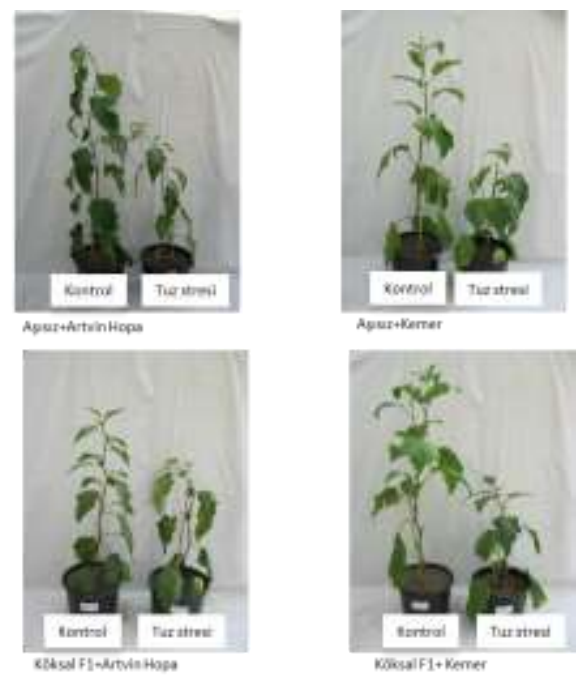

Şekil 2. Așllı ve aşısız patlıcan üzerine tuz stresinin etkileri.

Figure 2. Effects of salt stress on grafted and non-grafted eggplant.
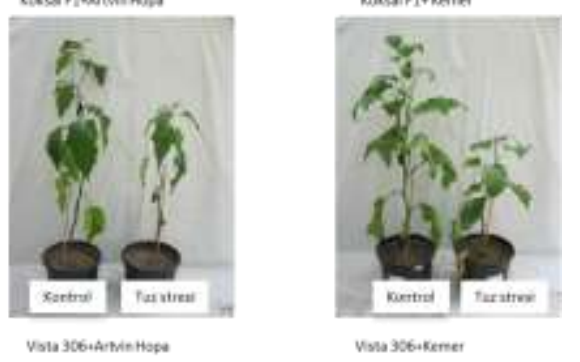
azalmakta ve sonuçta büyüme hızı yavaşlayabilmekte ve morfolojik özelliklerde kayıplar ortaya çıkmaktadır (Bahadur ve ark. 2011). Bununla beraber çalışmamızda bitki gelişimi ve verim üzerinde aşılama işleminin strese dayanım üzerine önemli bir etkisi olmuş, aş11 bitkilerde toplam verim ve verim parametrelerine ait özelliklerde kontrol bitkilerine göre yüksek değerler elde edilmiştir (Kıran ve ark. 2017a). SánchezRodríguez ve ark. (2012) anaç kullanımının, kuraklık stresinin verim ve meyve özellikleri üzerine olan olumsuz etkisini azaltabileceğini, Proietti ve ark. (2008) kuraklık stresi koşulunda anaç kullanımının, bitki gelişimini, verimi ve pazarlanabilir verim ile birlikte ortalama meyve ağırlığı gibi verim parametrelerini olumlu etkilediğini ifade etmişlerdir. Nitekim bu çalışmada da; kök yaş ağırlığı ile; yaprak alanı $\left(0.81^{* *}\right)$ ve ortalama meyve ağırlığı $\left(0.70^{* *}\right)$, ortalama meyve ağırlığı ile; kök yaş ağırlığı ve toplam verim $\left(0.70^{* *}\right)$, gövde boyu ile stoma iletkenliği $\left(0.80^{* *}\right)$, gövde kalınlığı ile yaprak alanı $(0.71 * *)$, toplam verim ile meyve kuru ağırlı̆̆ $1\left(0.70^{* *}\right)$ arasında pozitif yönde ve önemli seviyede korelasyonlar belirlenmiştir (Çizelge 1). Bununla birlikte titre edilebilir asitlik ile meyve kuru ağırlığ $\left(0.77^{* *}\right)$ ve meyve suyu EC $\left(0.70^{* *}\right)$, meyve suyu EC $\left(0.73^{* *}\right)$ ile meyve kuru ağırlığ 1 arasında önemli fakat daha düşük seviyelerde pozitif korelasyonlar ortaya çıkmıştır (Çizelge 1). Buna karşılık yaprak su potansiyelinin; gövde kalınlığı, gövde yaş ağırlığı, gövde kuru ağırlığı, kök yaş ağırlığı, yaprak alanı ve kök kuru ağırlığ1 arasında önemli yönde sergilediği ilişkinin yönü negatif bulunmuştur (sırasiyla: $0.83^{* *}, 0.81^{* *}, 0.74 * *, 0.69 * *, 0.65^{*}$, $0.64 *$ ). Benzer şekilde meyve kuru ağırlı̆g 1 ile; gövde boyu, toplam verim, gövde ve kök yaş ağırlıkları arasında da negatif yönlü nispeten düşük seviyelerde istatistiksel ilişkiler belirlenmiştir (sırasıyla: $0.73 * *, 0.70^{* *}, 0.61 *, 0.59^{*}$ ). Titre edilebilir asitlik ile; gövde boyu $\left(0.76^{* *}\right)$ ve stoma iletkenliği $\left(0.75^{* *}\right)$ arasında, C vitamini ile ortalama meyve ağırlığ $\left(0.73^{* *}\right)$ arasında nispeten düşük seviyede ve negatif yönlü ilişkiler göze çarpmıştır. Bununla birlikte kontrole göre aşılı bitkilerin stres koşulunda aşısız olanlara göre yaprak su potansiyellerini daha iyi koruyabildikleri dolayısıyla daha yüksek değerlere sahip oldukları görülmüştür. Nitekim Weng (2000), aşılanmış bitkilerde anacın su alım yeteneğinin kurak şartlara dayanım üzerine etkisinin önemli olduğunu bildirmektedir. Kuraklık nedeniyle ortaya çıkan meyve kuru ağırlığı, meyve suyunda EC ve C vitamini artışları, anaç/kalem etkileşimine bağlı olarak değişmekle birlikte çoğunlukla aşısız bitkilerde yüksek bulunmuştur (Kıran ve ark. 2018). Bu durumun, bitki dokularının kurak ortamlarda karbonhidrat biriktirme yeteneği, ozmotik dengenin korunması amacıyla iyon içeriklerinde ve buna bağlı olarak hücre özsuyu konsantrasyonunda meydana gelen değişim ve stres koşullarında ortaya çıkan serbest radikallere karşı korunmada etkili olan savunma mekanizmalarının da geliştirilmesiyle ilgili olabileceği bildirilmiştir (Huang ve ark. 2010).

\subsection{Tuz stresi altındaki patlican bitkilerinde incelenen parametreler arasinda elde edilen korelasyon bulgulart}

Tuz stresi sonrasında elde edilen bulgular ışı̆̆ı̆nda incelenen parametreler arasındaki ilişkilerin istatistiksel açıdan incelenmesinden elde edilen korelasyon katsayıları Çizelge 2'de verilmiştir. Gövde yaş ağırlığı ile gövde çapı, kök yaş ağırlığ1, gövde kuru ağırlığı, yaprak alanı, kök kuru ağırlığı ve stoma iletkenliği arasında istatistiksel bakımdan önemli düzeyde korelasyonlar belirlenmiştir (sırasıyla: $0.83^{* *}, 0.82^{* *}, 0.81^{* *}$,
$0.73^{* *}, 0.72^{* *}, 0.70^{* *}$ ) (Çizelge 2). Gövde kuru ağırlı̆̆ı; gövde kalınlığı ve yaprak alanı ile önemli seviyelerde ve aynı yönde istatistiksel ilişki göstermiş, korelasyon katsayıları $0.78^{* *}$ ve $0.74 * *$ olarak tespit edilmiştir (Çizelge 2). Bununla birlikte tuz stresi sonrasında ölçülen kök yaş ağırlığı değeri ile gövde kalınlığı, yaprak alanı ve kök kuru ağırlığı değerleri arasında da belirlenen korelasyonlar istatistiksel yönden oldukça yüksek bulunmuş ve bu ilişkilerin yönü yine aynı olmuştur (sırasıyla: $0.89 * *, 0.86 * *$ ve $0.80 * *$ ) (Çizelge 2). Benzer istatistiksel korelasyonlar; gövde kalınlığı ile kök kuru ağırlığı $(0.82 * *)$ ve yaprak alanı $\left(0.78^{* *}\right)$, titre edilebilir asitlik ile meyve kuru ağırlığ $1(0.79 * *)$, ortalama meyve ağırlığ 1 ile toplam verim $\left(0.73^{* *}\right)$ arasında ortaya çıkmıştır (Çizelge 2$)$. Tuz stresi altında kontrol bitkileri esas alındığında aşı1ı ve aşısız bitkilerin gövde yaş ve kuru ağırlıkları ile kök yaş ve kuru ağırlık, yaprak alanı, stoma iletkenliği değerlerinde azalmalar ortaya çıkmış, toplam verim ve verim parametrelerine ait değerler azalmıştır (Kıran ve ark. 2017b). Anaç kullanımı tuz stresi durumunda, patlıcan genotiplerinin yeşil aksam yaş ve kuru biyokütle kayıplarının azalmasını ve stoma iletiminin artmasını ve verim kayılarının azalmasını sağlamıştır. Tuzluluk stresi altında bitki biyokütle değerinin azalması, bitki bünyesine çok fazla miktarda alınan $\mathrm{Na}$ ve $\mathrm{Cl}$ iyonlarının ozmotik dengeyi bozması dolayısıyla bitki gelişiminin azalması ve verim kaybının ortaya çıkmasına bağlanmaktadır (Jacoby ve ark. 2016). Ayrıca patlıcanda aşılamanın toplam verimi, ortalama meyve ağırlığını artırıcı yönde etki yaptığı, aşılamanın meyve genişliğini artırdığı rapor edilmiştir (Passam ve ark. 2005). Bu durum anaçların kuvvetli kök sistemlerinin daha fazla su ve besin maddesi alabilmesi sayesinde verim kaybının aşılı bitkilerde daha az ortaya çıkması ile açıklanmıştır (Ruiz ve ark. 1997). Ayrıca meyve suyu EC; C vitamini ve meyve kuru ağırlığı ile önemli seviyelerde ve aynı yönlü istatistiksel ilişki göstermiş olup, oldukça yüksek korelasyon katsayıları vermiştir (sırasıyla: $0.93 * *$ ve $0.84 * *$ ) (Çizelge 2). C vitamini ile meyve kuru ağırlığı ve titre edilebilir asitlik arasında da benzer korelasyon ortaya çıkmıştır $\left(0.83^{* *}\right.$ ve $0.76 * *$ ) (Çizelge 2). Öte yandan meyve suyu EC değeri ile gövde yaş ağırlığı, stoma iletkenliği, gövde çapı ve yaprak alanı arasında ortaya çıkan korelasyonların önemli seviyede fakat negatif yönde olduğu görülmüştür. Meyve kuru ağırlığı ile gövde yaş ağırlığ $1\left(0.78^{* *}\right), \mathrm{C}$ vitamini ile gövde yaş ağırlığ 1 ve gövde kalınlığı $\left(0.79^{* *}\right.$ ve $\left.0.77 * *\right)$ arasındaki ilişkilerde de benzer durum gözlenmiştir (Çizelge 2). Çalışmamızda tuz stresi altındaki aşılı ve aşısız bitkilerde meyve kuru ağırlığı, meyve suyu EC ve C vitamini değerleri morfolojik özelliklere ait değerlerin aksine önemli derecede artmıştır. $\mathrm{Bu}$ artışlar meyve kuru ağırlığı ve meyve suyu EC değerlerinde aşısızlarda yüksek bulunmuştur (Kıran ve ark. 2018). Stres altındaki bitkilerin meyve iriliği olumsuz yönde etkilenirken meyve suyu EC oranı, meyve kuru ağırlığı ve titrasyon asitliği yükselmiştir. Nitekim Ünlükara ve ark. (2015) tarafindan tuzluluk koşullarında meyve kuru ağırlığının ve meyve suyu EC değerinin artabileceği ifade edilmiştir. Tuzluluk altında bitkiler ozmotik dengenin korunması amacıyla; $\mathrm{Na}$ ve $\mathrm{Cl}$ iyonlarının emilimini azaltarak $\mathrm{K}$ ve Ca iyonlarını alma yoluna gitmiş ve böylece hücre özsuyu konsantrasyonunda meydana gelen değişim meyve suyunda EC artışını sağlamıştır (Kıran ve ark. 2017a). Stres ortamında suyun yeterince alınamaması titrasyon asitliğinin yükseltmesine yol açmıştır. Aşılı bitkilerde su ve besin maddesinin alımı ve etkin kullanımı artmış ve meyvelerin titrasyon asitliği değerleri yükselmiştir. 
Çizelge 1. Kuraklık stresi altında yetişen aşılı patıcan bitkilerinin bazı özellikleri arasındaki korelasyon katsayıları.

Table 1. Correlation coefficients between some properties of grafted eggplants grown under drought stress.

\begin{tabular}{|c|c|c|c|c|c|c|c|c|c|c|c|c|c|c|c|c|c|c|c|c|}
\hline & & 1 & 2 & 3 & 4 & 5 & 6 & 7 & 8 & 9 & 10 & 11 & 12 & 13 & 14 & 15 & 16 & 17 & 18 & 19 \\
\hline 1 & Gövde Yaş. A $\breve{g}$. & 1.00 & & & & & & & & & & & & & & & & & & \\
\hline 2 & Gövde Kuru Ağ. & $0.79 * *$ & 1.00 & & & & & & & & & & & & & & & & & \\
\hline 3 & Kök Yaş Ă̆g. & $0.81 * *$ & $0.80 * *$ & 1.00 & & & & & & & & & & & & & & & & \\
\hline 4 & Kök Kuru Ağ. & $0.74 * *$ & 0.44 & $0.59 *$ & 1.00 & & & & & & & & & & & & & & & \\
\hline 5 & Gövde Boyu & 0.32 & 0.40 & 0.32 & 0.38 & 1.00 & & & & & & & & & & & & & & \\
\hline 6 & Kök Boyu & 0.47 & 0.32 & 0.24 & 0.23 & 0.17 & 1.00 & & & & & & & & & & & & & \\
\hline 7 & Gövde Kalınlığı & $0.85^{* *}$ & $0.85 * *$ & $0.65 *$ & 0.58 & 0.48 & 0.46 & 1.00 & & & & & & & & & & & & \\
\hline 8 & Yaprak Alanı & $0.80 * *$ & $0.84 * *$ & $0.81 * *$ & 0.49 & 0.35 & 0.47 & $0.71 * *$ & 1.00 & & & & & & & & & & & \\
\hline 9 & Stoma İletkenliği & 0.34 & 0.26 & 0.28 & 0.43 & $0.80 * *$ & 0.22 & 0.27 & 0.27 & 1.00 & & & & & & & & & & \\
\hline 10 & Yaprak Su Pot. & $-0.81 * *$ & $-0.74 * *$ & $-0.69 * *$ & $-0.64 *$ & -0.49 & -0.46 & $-0.83 * *$ & $-0.65 *$ & -0.32 & 1.00 & & & & & & & & & \\
\hline 11 & Toplam Verim & 0.45 & 0.43 & 0.51 & 0.25 & 0.47 & 0.04 & 0.25 & 0.48 & $0.60^{*}$ & -0.39 & 1.00 & & & & & & & & \\
\hline 12 & Ort. Meyve Ağ. & $0.62 *$ & 0.52 & $0.70 * *$ & 0.31 & 0.01 & 0.26 & 0.31 & $0.67 *$ & 0.16 & -0.33 & $0.70 * *$ & 1.00 & & & & & & & \\
\hline 13 & Ort. Meyve İriliği & 0.42 & 0.33 & 0.13 & 0.31 & 0.49 & 0.28 & 0.58 & 0.23 & 0.38 & -0.47 & 0.22 & -0.04 & 1.00 & & & & & & \\
\hline 14 & Meyve Kuru Ağ. & $-0.61 *$ & -0.52 & -0.49 & $-0.59 *$ & $-0.73 * *$ & 0.49 & -0.54 & -0.56 & -0.37 & $0.62 *$ & $-0.70 * *$ & -0.37 & -0.55 & 1.00 & & & & & \\
\hline 15 & Meyve Suyu EC & $-0.65 *$ & $-0.67 *$ & $-0.62 *$ & -0.47 & -0.52 & -0.10 & $-0.63 *$ & $-0.64 *$ & 0.26 & -0.53 & -0.54 & -0.42 & -0.34 & $0.73 * *$ & 1.00 & & & & \\
\hline 16 & Meyve Suyu pH & 0.57 & 0.58 & $0.59 *$ & 0.26 & 0.36 & 0.49 & $0.64 *$ & 0.53 & -0.38 & 0.21 & 0.11 & 0.31 & 0.36 & -0.29 & -0.33 & 1.00 & & & \\
\hline 17 & TSČKM & $-0,05$ & $-0,30$ & $-0,07$ & 0,10 & $-0,57$ & 0,01 & $-0,34$ & $-0,06$ & $-0,38$ & 0,21 & $-0,06$ & 0,28 & $-0,40$ & 0,16 & 0,33 & $-0,19$ & 1,00 & & \\
\hline 18 & $\mathrm{TA}^{3}$ & -0.47 & -0.40 & -0.42 & -0.45 & $-0.76 * *$ & -0.24 & -0.48 & -0.41 & $-0.75 * *$ & 0.51 & -0.54 & -0.23 & -0.54 & $0.77 * *$ & $0.70 * *$ & -0.57 & 0.25 & 1.00 & \\
\hline 19 & C Vitamini & -0.51 & $-0.66^{*}$ & -0.52 & -0.16 & -0.19 & -0.13 & -0.47 & $-0.65^{*}$ & -0.16 & 0.34 & $-0.67 *$ & $-0.73 * *$ & -0.26 & 0.43 & 0.45 & -0.18 & -0.06 & 0.24 & 1.00 \\
\hline
\end{tabular}

**\%1 düzeyinde, ${ }^{*} \% 5$ düzeyinde önemli.

Cizelge 2. Tuz stresi altında yetişen aşılı patlıcan fidelerinin bazı özellikleri arasındaki korelasyon katsayıları.

Table 2. Correlation coefficients between some properties of grafted eggplants grown under salt stress.

\begin{tabular}{|c|c|c|c|c|c|c|c|c|c|c|c|c|c|c|c|c|c|c|c|c|}
\hline & & 1 & 2 & 3 & 4 & 5 & 6 & 7 & 8 & 9 & 10 & 11 & 12 & 13 & 14 & 15 & 16 & 17 & 18 & 19 \\
\hline 1 & Gövde Yaş. Ağ. & 1.00 & & & & & & & & & & & & & & & & & & \\
\hline 2 & Gövde Kuru Ă̆. & $0.81^{* *}$ & 1.00 & & & & & & & & & & & & & & & & & \\
\hline 3 & Kök Yaş Ağ. & $0.82 * *$ & $0.77 * *$ & 1.00 & & & & & & & & & & & & & & & & \\
\hline 4 & Kök Kuru Ăg. & $0.72 * *$ & $0.66^{*}$ & 0.80 ** & 1.00 & & & & & & & & & & & & & & & \\
\hline 5 & Gövde Boyu & 0.45 & 0.16 & 0.39 & 0.27 & 1.00 & & & & & & & & & & & & & & \\
\hline 6 & Kök Boyu & 0.46 & 0.54 & 0.49 & 0.40 & 0.20 & 1.00 & & & & & & & & & & & & & \\
\hline 7 & Gövde Kalınlı̆̆ı & $0.83 * *$ & $0.78 * *$ & $0.89 * *$ & $0.82 * *$ & 0.29 & 0.50 & 1.00 & & & & & & & & & & & & \\
\hline 8 & Yaprak Alanı & $0.73 * *$ & $0.74 * *$ & $0.86^{* *}$ & $0.59 *$ & 0.37 & 0.41 & $0.78^{* *}$ & 1.00 & & & & & & & & & & & \\
\hline 9 & Stoma İletkenliği & $0.70^{* * *}$ & 0.38 & $0.64 *$ & $0.67 *$ & $0.62 *$ & 0.14 & $0.65^{*}$ & 0.50 & 1.00 & & & & & & & & & & \\
\hline 10 & Yaprak Su Pot. & -0.36 & -0.24 & -0.39 & -0.35 & -0.22 & -0.11 & -0.36 & -0.22 & -0.40 & 1.00 & & & & & & & & & \\
\hline 11 & Toplam Verim & $0.64 *$ & $0.66^{*}$ & 0.37 & 0.35 & 0.23 & 0.33 & 0.52 & 0.44 & 0.37 & -0.03 & 1.00 & & & & & & & & \\
\hline 12 & Ort. Meyve A $\breve{g}$. & 0.40 & 0.36 & 0.18 & 0.27 & 0.21 & 0.06 & 0.29 & 0.22 & 0.34 & 0.09 & $0.73 * *$ & 1.00 & & & & & & & \\
\hline 13 & Ort. Meyve İriliği & 0.47 & 0.25 & 0.14 & 0.27 & 0.19 & 0.26 & 0.26 & -0.08 & 0.45 & -0.37 & 0.41 & 0.45 & 1.00 & & & & & & \\
\hline 14 & Meyve Kuru Ağ. & $-0.78^{* *}$ & -0.58 & $-0.62 *$ & -0.44 & $-0.69 *$ & 0.53 & $-0.62 *$ & $-0.62 *$ & $-0.65^{*}$ & 0.36 & $-0.67^{*}$ & -0.50 & -0.48 & 1.00 & & & & & \\
\hline 15 & Meyve Suyu EC & $-0.80 * *$ & -0.58 & $-0.69^{*}$ & $-0.61 *$ & $-0.65^{*}$ & -0.44 & $-0.73 * *$ & $-0.63^{*}$ & $-0.76 * *$ & 0.17 & -0.58 & -0.48 & -0.34 & $0.84 * *$ & 1.00 & & & & \\
\hline 16 & Meyve Suyu pH & 0.52 & 0.42 & $0.62 *$ & 0.29 & 0.45 & 0.53 & 0.43 & 0.51 & 0.31 & -0.13 & 0.15 & -0.11 & 0.04 & -0.58 & -0.57 & 1.00 & & & \\
\hline 17 & TSÇKM & -0.58 & -0.35 & -0.27 & -0.40 & -0.47 & -0.33 & -0.38 & -0.27 & -0.59 & 0.26 & -0.37 & -0.37 & $-0.61^{*}$ & $0.62 *$ & $0.59^{*}$ & -0.20 & 1.00 & & \\
\hline 18 & TA & $-0.65^{*}$ & -0.47 & -0.54 & -0.43 & $-0.63 *$ & -0.36 & -0.51 & -0.52 & $-0.61 *$ & -0.04 & -0.51 & -0.35 & -0.28 & $0.79 * *$ & $0.83^{* *}$ & $-0.67 *$ & 0.56 & 1.00 & \\
\hline 19 & C Vitamini & $-0.79 * *$ & $-0.63 *$ & $-0.62 *$ & -0.51 & -0.48 & -0.53 & $-0.77 * *$ & -0.56 & $-0.66^{*}$ & 0.22 & $-0.67 *$ & -0.44 & -0.49 & $0.83 * *$ & $0.93^{* *}$ & -0.53 & 0.57 & $0.76^{* * *}$ & 1.00 \\
\hline
\end{tabular}

19 C Vitamini $\quad-0.79 * *$ 


\section{Sonuç}

Patlıcan genotiplerinin farklı anaçlar üzerine aşılanmasıyla elde edilen aşı kombinasyonlarının kuraklık ve tuz stresine karşı ayr1 ayr1 gösterdikleri morfolojik ve fizyolojik tepkilerin ve verim-kalite özelliklerinin birbirleriyle ilişkilerinin incelendiği çalışmada; her iki stres ortamında gövde yaş-kuru ağırlıkları, kök yaş ağırlığı ve gövde kalınlığının diğer morfolojik özelliklerin çoğu ile aynı yönde ve yüksek seviyede istatistiksel ilişkiler sergiledikleri belirlenmiştir. Ayrıca meyve kuru ağırlığının, meyve suyu EC ve titrasyon asitliği ile birlikte, tuz ve kuraklık stresine bitkilerin tolerans özelliği üzerinde etkili özellik olarak değerlendirilebileceği sonucuna varılmıştır.

\section{Kaynaklar}

Bahadur A, Chatterjee A, Kumar R, Singh M, Naik PS (2011) Physiological and biochemical basis of drought tolerance in vegetables. Vegetable Science 38(1): 1-16.

Cemeroğlu B (1992) Meyve ve sebze işleme endüstrisinde temel analiz metodları. Biltav Yayınları, Ankara, s. 380.

Gaion LA, Monteiroa CC, Rodrigues Cruza FJ, Rossattoa DR, LópezDíazb I, Carrerab E, Limac JE, Peresd LEP, Carvalho RF (2018) Constitutive gibberellin response in grafted tomato modulates rootto-shoot signaling under drought stress. Journal of Plant Physiology 221: 11-21.

Güçdemir İH (2006) Türkiye Gübre ve Gübreleme Rehberi. Toprak Gübre ve Su Kaynakları Merkez Araștırma Enstitüsü Yayınları, Ankara, s. 235-245.

Huang Y, Zhilong B, Sanpeng H, Hua B, Zhen A, Zhixiong L (2010) Improving cucumber tolerance to major nutrients induced salinity by grafting onto Cucurbita ficifilia. Environmental and Experimental Botany 69(1): 32-38.

Jacoby RP, Che-Othman MH, Millar AH, Taylor NL (2016) Analysis of the sodium chloride-dependent respiratory kinetics of wheat mitochondria reveals differential effects on phosphorylating and non-phosphorylating electron transport pathways. PlantCell Environment 39: 823-833.

Kıran S, Kuşvuran Ş, Ateş Ç, Ellialtıoğlu ŞŞ (2017a). Aş1lı ve aşısız patlıcan bitkilerinin su noksanlığı koşullarındaki bazı fizyolojik özellikleri ve verim parametrelerine ilişkin incelemeler. Toprak Su Dergisi 6(2): (18-25).

Kıran, S, Ateş Ç, Kuşvuran Ş, Ellialtıoğlu ŞŞ (2017b) Kuraklık ve tuzluluk stresine dayanım üzerine farklı anaç ve çeşit kombinasyonlarından oluşan aşılı fide kullanımının etkilerinin belirlenmesi. TAGEM Sonuç Raporu. Proje No: TAGEM/TSKAD/14/A13/P02/02.

Kıran S, Kuşvuran Ş, Ateş Ç, Ellialtioğlu ŞŞ (2018) Tuzluluk ve su noksanlığı stresi altında yetiştirilen farklı patlıcan anaç/kalem kombinasyonlarında bazı meyve kalite özelliklerine ait değişimler. Derim 35(2): 111-120.

Koleška I, Hasanagić D, Todorović V, Murtić S, Maksimović I (2018) Grafting influence on the weight and quality of tomato fruit under salt stress. Annals of Applied Biology 172(2): 187-196.

Kyriacou MC, Rouphael Y, Colla G, Zrenner R, Schwarz D (2017) Vegetable grafting: The implications of a growing agronomic imperative for vegetable fruit quality and nutritive value. Frontiers in Plant Science 8(741): 1-23.
Passam HC, Stylianou M, Kotsiras A (2005) Performance of eggplant grafted on tomato and eggplant rootstocks. European Journal of Horticultural Science 70: 130-134

Penellaa C, Nebauerb SG, López-Galarzab S, Quiñonesa A, San Bautistab A, Calatayuda A (2017) Grafting pepper onto tolerant rootstocks: An environmental-friendly technique overcome water and salt stress. Scientia Horticulturae 226: 33-41.

Proietti S, Rouphael Y, Colla G, Cardarelli M, De Agazi, M, Zacchini M, Rea E, Moscatello S, Battistelli A (2008) Fruit quality of miniwatermelon as affected by grafting and irrigation regimes. Journal of the Science of Food and Agriculture 88: 1107-1114.

Radicetti E, Massantini R, Campiglia E, Mancinelli R, Ferri S, Moscetti $\mathrm{R}$ (2016) Yield and quality of eggplant (Solanum melongena L.) as affected by cover crop species and residue management. Scientia Horticulturae 204: 161-171.

Rady MM, El-Azeem MMA, El-Mageed TAA, Abdelhamid MT (2018) Integrative potassium humate and biochar application reduces salinity effects and contaminants, and improves growth and yield of eggplant grown under saline conditions. International Journal for Empirical Education and Research 1(2): 37-36.

Rezene Y, Gebeyehu S, Zelleke H (2013) Morpho-physiological response to post-flowering drought stress in small red seeded common bean (Phaseolus vulgaris L.) genotypes. Journal of Plant Studies 2(1): 36-41.

Richards LA (1954) Diagnosis and Improvement of Saline and Alkali Soils . U.S.Dept. Agr. Handbook 60: 105-106.

Ruiz JM, Belakbir A, López-Cantarero I, Romero L (1997) Leafmacronutrient content and yield in grafted, melon plants. A model to evaluate the influence of rootstock genotype. Scientia Horticulturae 71: 227-234.

Sánchez-Rodríguez E, Leyva R, Constán -Aguilar C, Romero L, Ruiz J $M$ (2012) Grafting under water stress in tomato cherry: improving the fruit yield and quality. Annals of Applied Biology 161(3): 302312.

Talhouni M, Sönmez K, Ellialtıŏlu ŞŞ, Kuşvuran Ş (2017) Tuz stresi altında yetiştirilen aşılı patlıcan bitkilerinde bazı bitki ve meyve özelliklerinin incelenmesi. Akademik Ziraat Dergisi 6: 71-80.

Ünlükara A, Kurunç A, Cemek B (2015) Green long pepper growth under different saline and water regime conditions and usability of water consumption in plant salt tolerance. Journal of Agricultural Sciences 21: 167-176.

Weng J H (2000) The role of active and passive water uptake in maintaining leaf water status and photosynthesis in tomato under water deficit. Plant Production Science 3(3): 296-298.

Yaşar F (2003) Some of antioxidant enzyme activity investigation as in vivo and in vitro of eggplant genotypes under salt stress. $\mathrm{PhD}$ Thesis, University of Yuzuncu Y1l, Van.

Yetişir H, Garip Y, Sarı N (2004) Grafting in vegetables. Bahçe 33(12): 27-11.

Zhou R, Yu X, Ottose CO, Rosenqvist E,Zhou L, Wang Y,Yu W, Zhou T,Wu Z (2017) Drought stress had a predominant effect over heat stress on three tomato cultivars subjected to combined stress. https://doi.org/10.1186/s12870-017-0974-x.pdf. Erişim 4 Haziran 2019. 